This item was submitted to Loughborough's Research Repository by the author.

Items in Figshare are protected by copyright, with all rights reserved, unless otherwise indicated.

\title{
Understanding physical activity in spinal cord injury rehabilitation: translating and communicating research through stories
}

PLEASE CITE THE PUBLISHED VERSION

http://dx.doi.org/10.3109/09638288.2013.805821

\section{PUBLISHER}

Taylor \& Francis (@ Informa UK Ltd)

VERSION

AM (Accepted Manuscript)

\section{PUBLISHER STATEMENT}

This work is made available according to the conditions of the Creative Commons Attribution-NonCommercialNoDerivatives 4.0 International (CC BY-NC-ND 4.0) licence. Full details of this licence are available at: https://creativecommons.org/licenses/by-nc-nd/4.0/

\section{LICENCE}

CC BY-NC-ND 4.0

\section{REPOSITORY RECORD}

Smith, Brett M., Anthony Papathomas, Kathleen A.M. Ginis, and Amy E. Latimer-Cheung. 2019. "Understanding Physical Activity in Spinal Cord Injury Rehabilitation: Translating and Communicating Research Through Stories". figshare. https://hdl.handle.net/2134/17178. 
Understanding Physical Activity in Spinal Cord Injury Rehabilitation:

Translating and Communicating Research Through Stories

\section{By}

Smith, B., ${ }^{1}$ Papathomas, A., ${ }^{1}$ Martin Ginis, K. A. ${ }^{2}$ \& Latimer-Cheung, A. E. ${ }^{2}$

${ }^{1}$ Loughborough University

School of Sport, Exercise and Health Sciences

Peter Harrison Centre for Disability Sport

Loughborough

Leicestershire

United Kingdom

LE11 3TU

${ }^{2}$ McMaster University

Department of Kinesiology

Ivor Wynne Centre

1280 Main Street West

Hamilton, ON L8S 4K1

Canada

All correspondence in relation to this article should be directed to Dr Brett Smith

(B.M.Smith@lboro.ac.uk) 
Abstract:

Purpose: The purpose of this paper is to develop an evidence-based resource for knowing and communicating the complexities involved for both males and females in implementing and sustaining a physically active lifestyle shortly after SCI.

Methods: Synthesizing a set of qualitative and quantitative studies with over 500 spinal cord injured people, the paper represents research utilizing the genre of ethnographic creative non-fiction. This genre of representation holds enormous potential for researchers in terms of disseminating their findings to diverse audiences beyond the academy, and having real impact.

Results: The ethnographic creative non-fictions show together for the first time the barriers, determinants, benefits, trajectories, emotions, fears, preferred methods and messengers for delivering important physical activity information to men and women with a SCI.

Conclusion: The paper contributes to knowledge by showing the embodied complexities involved when in rehabilitation for both males and females in implementing and sustaining a physically active lifestyle shortly after SCI. It also makes a contribution to practice by providing researchers, health care professionals, and disability user-groups with a theory and evidence based resource to assist in informing, teaching and enabling people living with SCI to initiate and maintain a physically active lifestyle. Stories may be a highly effective tool to communicate with and to influence spinal cord injured people's activity.

Keywords: narrative, vignette, ethnographic creative non-fiction, physical activity, health promotion 
There is small but growing evidence that regularly participating in physical activity (i.e. movement of the body that results in energy expenditure) or sport (i.e. rule governed, competitive, and structured activity) has health and wellbeing benefits for people with a spinal cord injury (SCI) [1-6]. Despite this, following SCI there is a reduction or cessation of participation in physical activity and sport among people [7, 8]. Spinal cord injured people are also often sedentary and daily physical activity levels are low among both men and women $[7,8]$. As such, what is needed is not just more of the same theory and evidencebased work but also research that develops new approaches to knowing SCI, physical activity, and sport as well as evidence-based practical resources that might effectively communicate this knowledge to people and mobilize shifts in how they perceive and incorporate healthier behaviours into their lives over the life course.

Set against this need, the purpose of this paper is to produce a novel evidence-based resource for knowing, translating, and communicating the complexities involved for both males and females in implementing and sustaining a physically active lifestyle shortly after SCI. To do this we rigorously synthesise findings from a large body of empirical work [1-3, 5-26] conducted on becoming and staying physically active following SCI through an innovative form of scientific representation known as ethnographic creative non-fiction. This is a type of report - a composite narrative vignette - that tells a story which is grounded in research findings and composed using the techniques of fiction [27, 28]. Thus, the story produced is 'real' and not 'imagined' or 'unscientific'. It is, as Caulley [29] put it, “deeply committed to the truth” [p. 426] and a legitimate evidence-based tool for scientists to translate scientific knowledge in ways that can deeply engage readers. Many others agree [30-34].

Drawing on qualitative and quantitative studies with over 500 spinal cord injured people [1-3, 5-26], in what follows are two ethnographic creative non-fictions that uniquely 
show the barriers, determinants, benefits, trajectories, emotions, fears, preferred methods and messengers for delivering important physical activity information to men and women with a SCI when in the context of rehabilitation. The paper extends knowledge by developing theory and evidence-based stories that, for the first time, shows rather than tells the complexities of developing and practicing a physically active lifestyle during SCI rehabilitation. It also contributes to practice by providing researchers, health care professionals, and disability groups with a user-friendly resource to assist in informing, teaching and enabling people living with SCI to initiate and maintain a physically active lifestyle.

\section{Method}

The research was granted university ethics approval. Before describing how the ethnographic creative non-fictions were developed, it is first important to note the reasons as to why this genre of representation was used. First, the genre of ethnographic creative nonfiction allows researchers to gather together an array of research findings and represent these in one paper without losing the richness or complexity of what was found [30-31]. In so doing, a research paper can be produced that not only deepens theory, but also delivers substantial knowledge in detailed, evocative, and nuanced ways.

Second, partly due to the method used and how research is represented, much work on disability, sport and physical activity is disembodied, emotionally thin, and lacking voices socially interacting in dialogue with each other [5]. An ethnographic creative non-fiction, however, is a means to address the embodied, affective, and social relational nature of disability, sport, and physical activity. In achieving this, the research can be more memorable, more human, and more understandable. It can open up, rather than close down, different ways of being and possible worlds in a manner that provokes people to think with and not just about research. As part of this, a shift may be mobilized in how people perceive and incorporate healthier behaviours into their lives over the life course. 
Third, an ethnographic creative non-fiction has the benefit of being able to reach multiple audiences instead of only academics. The traditional ways to represent qualitative research (known as a realist tale) and quantitative research (known as the scientific tale) deliver important knowledge when done well [27-28, 31]. However, due to the highly specialized academic terminology used, the scientific and realist tale are comprehensible largely to academic audiences only, thereby limiting the communication of findings and knowledge translation process [27, 31, 34]. An ethnographic creative non-fiction has, however, the strength of being highly accessible to many people beyond academia [27, 28-29, 32]. It is more accessible because good ethnographic creative non-fictions are stories that use everyday language, are emotionally engaging, contextualize experiences, promote meaningmaking, stimulate imagination, resonate with people, show theory, and humanize the mind, behaviour and action. One implication of highly accessible research is that knowledge can be disseminated and translated to more people. Another possible implication is that the research will have wide and significant practical impact. This could include informing, teaching and enabling people living with SCI to initiate and maintain a physically active lifestyle. It might involve helping people perceive and incorporate healthier behaviours into their lives over the life course.

The ethnographic creative non-fictions were developed through a multi-stage process that began with a synthesis of findings from a large body of published quantitative and qualitative research we have conducted on SCI, sport, and physical activity for over ten years [see 1-3 5-26]. Based on rigorously analysed life history interviews, participant observation, focus groups, intervention studies, randomized control trials, scoping reviews, narrative reviews, and validated questionnaires, and theoretically informed by narrative and cognitive theory, findings of this research can be summarised as follows. Several narratives that people with a SCI drew on to shape their experiences have been identified [6, 9-14, 16-17, 26]. A 
dominant narrative was the restitution narrative that has the plot of, 'Yesterday I was ablebodied, today I'm disabled, and some point in the future I will be able-bodied again'. Another narrative was the chaos narrative in which the teller imagines life never getting better [13]. Our research also revealed the work each narrative can do on and for people, such as shaping health beliefs, conducting physical activity behaviours, performing resilience, and upholding masculine identities [6, 11-13, 16-17, 26]. Further, analyses of the qualitative and quantitative data found that being regularly active was associated with reduced cardiovascular and metabolic risk profiles, reduced pain, fatigue and depression, increased functional independence, social integration and gainful employment, and improved quality of life, subjective well-being (e.g., self-esteem, mood, and self-confidence), psychological wellbeing (e.g., personal growth), and body-self compassion [1-3, 5-6, 12, 18, 24, 26].

Despite these benefits, our research also found that physical activity and sporting participation rates among people with SCI were very low [7-8]. Reasons for this included inaccessible environments, negative attitudes, perceived lack of intrinsic motivation, time, and social support, cost, transport difficulties, past experiences of sport, the physical body (e.g., the presence of pressure ulcers), sparse health promotion initiatives, locking into an approach in which one cares about their own health but not too much, and a dearth of information about what sport or exercise is available, where it can be done, and how [1-3, 5$6,14-16,17-18,24]$. In light of all this, intervention research to increase physical activity in the SCI community was conducted [20]. Here, intentions, planning, motivation, and social comparison strategies were shown to be important for moving people toward engaging in physical activity or sport, or hindering their progress. We have further suggested who the credible messengers are (e.g., peers and health professionals) and what the effective methods are (e.g., Internet and stories) for conveying health messages to people with a SCI [6, 21-22]. 
Moreover, the number of minutes a day of physical activity people with SCI perform has been estimated [7-8] and evidence-based exercise guidelines have been developed [23].

To create the ethnographic creative non-fictions - to identify what should be included in each story and why - the above findings were synthesized using what can be described as the systematic search and review method [35]. This is a technique that aims for exhaustive, comprehensive searching of research to produce a 'best evidence synthesis' of findings. It is valuable for its comprehensiveness and inclusivity of different study designs, and its ability to condense scientific findings from multiple studies. Through this method, differences in how a physically active lifestyle is initiated and maintained, and what is involved in hindering and promoting this physical, social, and psychological process, were identified between men and women. As such, the decision was made to write two stories to reflect these differences.

Following this procedure, the story writing began. This was an iterative process. Developed by the first author, the stories were first crafted, edited, and re-crafted on multiple occasions by drawing on the findings from the systematic search and review method, and using literary techniques to turn and weave these facts into a story that might engage readers. For example, composite characters in embodied dialogue were constructed to reveal what was found and how people interact to constitute embodied realties. The language used by each character, such as the metaphors employed, and plot lines drawn on were also grounded in the findings. Time was telescoped in order to produce a story that could communicate results in concise and evocative ways.

Once completed, both stories were then shared with the other authors who, as critical friends, checked for the accuracy of research findings within each story along with the cohesiveness, evocation, concision, illumination, social significance, and aesthetic value of them. Feedback resulted in further editing of the stories. Once each person independently confirmed the goodness of the stories, the stories were shared with 4 men and 4 women with 
a SCI as well as with 8 spinal injury rehabilitation health professionals. All reviewed the stories for accuracy and their ability to engage. All confirmed the accuracy of the stories. Each was also verified as being very engaging. This said, some minor changes were suggested in terms of how characters spoke and the complexity of several sentences. Based on this feedback, the stories were again revised and fed back to spinal cord injured people and health professionals who reviewed each again. All confirmed the goodness of the stories.

With these points in mind, what follows are two ethnographic creative non-fictions in the form of short stories.

\section{Jennifer, Cathy and Sarah}

“How are you Jennifer?” asks Cathy softly.

"Y’know, good days, bad days.” After taking a sip of her warm tea through a straw, Jennifer adds, “I’m worried, anxious, about leaving here. I know I should be looking forward to getting out of here. I've a husband and son waiting for me, who are looking forward to me coming home. I miss them. I should be grateful that I'm still alive too. But, I feel, I feel this gurgling in me, this deep sense of sickly anxiety about leaving.”

Stretching out her hand, and gently squeezing Jennifer's hand, Cathy says "I felt the same. I don't have a family like you do. But I both wanted to get out of this place while not wanting to leave. For me, when I look back, I felt secure in here.” Facing Jennifer across the round table in the half empty café in the spinal rehabilitation unit, Cathy adds. "It's ok to feel anxious.”

“Thanks. I think too, if I'm honest, I'm worried about being a wife and mother again. I'm in a wheelchair for goodness sake. How can I keep up with my son? Look after him when he falls? Cuddle him just after he's had a nightmare? And how will my husband feel about me?” Lowering her voice slightly, she adds, “We’ve always had a good sex life, and I really pride myself on how I look. I've never had to be active, diet, do exercise. Being a young 
working mom has always helped me stay trim. But look at me Cathy. I'm plump now. I feel, I feel, I don’t feel sexy. I don’t feel like the woman I was, or the woman my husband fell in love with. I know all the stuff the psychologists have said about relationships. I know all that. But in here,” Jennifer says releasing her hand from Cathy's gentle hold and placing it on her heart, "In here, I feel lost.”

“If I say that’s normal Jennifer, I’d sound patronizing. But trust me when I say I’ve heard other women say similar things. Not all, but you're not alone. You're not alone.”

“What would I do without you?” Jennifer says.

Smiling, Cathy cuts in, “Ahhh, stop that. We need to stick together. It’s not easy being a disabled woman. And it's a lot harder out there, in the real world. You'll find that, once you're discharged. But we're there for each other. And if you want I'll put you in touch with other women who are married and in a wheelchair.”

"I may take you up on that later. How have you managed to look so good? How have you managed to get in shape? Sorry, I’ve wanted to ask that for a long time,” admits Jennifer.

“No, no. Sorry, I’m surprised you asked,” Cathy says.

"Why?”

"I suppose I always thought of you as a young feminist, someone who questions what's normal, and someone who questions how women should behave or should look like.” Shuffling in her wheelchair with the help of her elbows on the arms of her chair, Cathy says with a mischievous smile, “And I’ve seen those disapproving looks you give sometimes at the stick thin women in the magazines I've brought in. I’ve seen it!”

With a giggle, Jennifer says “Me?! Never!” With a gentle smile she continues, "Seriously, what I have also noticed is that there are usually no disabled women in the magazines you pass on to me. Yet we are everywhere. It's wrong. And we need to do something about this.” 
“Agreed,” says Cathy.

“Ah, hold on a second.” Turning slightly, and looking across at the large windowed café doors, Jennifer notes, “Ah, its Sarah. I’ve been meaning to introduce you to her for some time. She was brought in a few weeks after me. Broke her neck in a fall, and she's not dealing with things too well. I've not seen her have many visitors either. Would you mind if I invited her to join us?”

"Of course, of course," says Cathy with a nod. "Invite her over."

“Sarah, Sarah, join us if you want,” Jennifer calls in a voice just loud enough for her to hear.

A few moments later Sarah arrives at the round table, and pushes her wheelchair slightly under it.

"Sarah, this is Cathy. Cathy, Sarah."

“Nice to meet you. You're Jennifer’s guardian angel, she tells me,” says Sarah with a gentle smile.

“That’s nice. But in all honesty, I think she’s as big a help to me as I might be for her. I'm supposed to be her peer support!” adds Cathy with laugh.

“And you?” butts in Jennifer smiling. Turning to Sarah, she adds, “How are you?”

“So, so. Feeling a little down, a little, a little despondent, if I’m honest. I’ve just come back from physio. We were talking about what I need to do when I leave here.”

“That’s with Krista, right?” interjects Jennifer, before adding for the benefit of Cathy. "She’s the new physio. She’s really up on the latest things, really good, forward thinking."

“Yeah, that’s her,” confirms Sarah. "I like her. But we were talking about doing exercise, being more active now, and planning on being physically active when I leave. I'm struggling to feel motivated about it all. It's not so much worried me. But, I was never an exerciser before my accident. And I've hated sports since I was in public school. Hated it. 
Being active wasn't me. I really wasn't interested. Now, on top of everything else, I'm being advised to take up exercise, and be active. It's another thing to do. It seems never ending what we should and shouldn't do. And progress is just so small, sometimes I feel as if I've gone backward in physio. How is exercise going to make any big difference?”

“I wonder that too,” says Jennifer. "I was fairly active before my accident. I loved my horse riding of course. But I'm not sure exercising, sports, all that is for me either. My physiotherapist hasn't said anything to me though. No one really has. What do you make of it all Cathy? Load of nonsense?” With the corners of her mouth curving into a smile, Jennifer quickly adds, "Cathy’s a bit of a cynic sometimes.”

“I can be,” Cathy says with a wry smile. "What do I make of it? Well, Krista, your physio, has a point. The experts have shown there are so many benefits to being active physically, and equally it's not good for you if you don't move around. I’d agree. My experiences of being active now, as well what I’ve heard and seen from other spinal women, support all this. When I went through rehab, no one told me to be active. They told me lots of things I should and should not do. But physical activity or sport was not talked about. I think that's a shame as I look back. Don’t get me wrong. Like you, I wasn’t particularly interested in exercise. I was very uninterested in sport. Now though things are different, and what a difference.”

“Such as?” asks Sarah.

“Well, I’ve been exercising for about 8 months now. At first, it was tough. I gave up a few times. I had seen from other disabled women there are benefits to being active, and I thought things would happen overnight. They didn’t, and I stopped a few times. There were other things too that made a difference. Where I first lived, it was a long way to travel to a gym, and there were no bus stops close by my house either. The gym I did end up joining was ok, but most of the equipment wasn't suitable for people in wheelchairs. So the facilities 
weren't perfect. And during the winter, I found it tough too. It wasn't just the snow, or moving around in the cold that made going to the gym difficult. Truth be told, I was a little concerned about my safety too.”

“That’s understandable,” says Jennifer in a soft voice.

“I’d agree,” adds Sarah before gently saying, “I’m not surprised you gave up. It sounds as though there is barrier after barrier."

“I won’t deny there aren’t a few barriers. But what I realized, thanks to a friend, was that I really hadn’t thought exercising through. Most things in my life now are planned to a 'T', as you'll appreciate when you leave. But I didn’t really plan about where best to exercise, when, how, or even think about different types of activity.”

“And so what happened?” asks Sarah, leaning forward.

“A friend visited. And I opened up about how awful I was feeling, physically, mentally. I was sick of being offered just pills by the doctors, and I didn’t feel like a woman anymore. I felt as though life was passing me by. I didn’t like my body, and who I was anymore. My friend listened and after a while we made a plan about changing my life. Part of the plan was to stick at exercising, and be active.”

“And how did you do that? Where did you start? I just couldn’t even contemplate thinking about it now,” Jennifer proclaims.

"But this is precisely the time to start thinking about it. Plans need putting in place now. What I did, well, I found the Canadian Paraplegic Association on the internet and contacted them. They offered me advice. A big help. They knew which gyms were best for wheelchair users. They also pointed me in the direction of more specialist organizations such as SCI Action Canada and asked if I had insurance. Thankfully I have. They said contact them. I did. The person I dealt with was nice. He gave me some good advice on costing 
equipment. All that though would have been more useful at the beginning, when I was still in rehab.”

“Why?” asks Jennifer

“I spent a lot of money on equipment that wasn’t right, and going to a gym that wasn’t really of any use. I look back at how clueless I was. If I’d worked with my lawyer and insurance company when I was in rehab to cost the right equipment up, and asked them about what other clients had found good, I know exercising would have been much easier. It might be wise now to speak with your lawyer about all this Jennifer.”

“I just might. I'm still not 100\% convinced though Cathy. I don't want to be the cynical one now, but come on, you're not telling me that exercising, being physically active, turned your life around and made you be this happy person now. I don’t buy that.”

“Like everyone, I have good days and bad days,” Cathy says. With a nod, she adds, “And I agree. Exercise and being active isn’t like a miracle. It certainly didn’t change my life overnight. But, it has played a big part in helping me feel better about myself. I really do feel a lot more alive, and take care of my body much better. My self-esteem has improved, and my friends tell me I'm a lot more fun to be around, and I have confidence now. When I exercise I feel as though I'm accomplishing something too, and not just lying around. Mentally I feel better. And I’ve made some new, good friends through going out and being active.”

"Krista, the physio, also mentioned to me that the experts had found there were physical benefits too. Is that nonsense?” asks Sarah.

"No, no. Bear in mind none of this happens overnight. But being regularly active physically, well, I've noticed so many benefits. I know lots of other spinal injured women have too. For example, being active has helped me control the pain I've had. It helps me 
prevent pressure sores. And it has been good for bladder and bowel control. I'm not as congested. And I have to think about my future. You have a son and husband Jennifer.” "Yeah.”

“You have to be there for yourself. But you've also got to be there for your family. You'll want to be able to do things with them. Being a mom requires energy I hear! My friends with kids tell me that exercising has helped them feel calmer. It’s given them more energy. And another real incentive to exercise for some of my friends is that they still want to be around for their kids and family as they grow older. I want to be around for my friends too.

"So being active is good as we grow older. Experts tell us it helps lessen muscle loss, reduce body fat, improve flexibility, and decrease blood clots. They have also found that being active deceases the risk for heart disease and diabetes. And my friends are telling me how energized they feel, how rejuvenated they are after exercising. They’ve noticed other benefits too. Not only can they push themselves up steeper ramps, but they feel more confident, and can see a brighter future. I've really noticed changes in them. And they tell me they take much less medication, sleep better, and feel they have a real purpose in life.”

With a warm smile, Jennifer cut in, "So exercise is a miracle cure! To be honest, I'm contemplating it. But come on, it’s not easy.”

“You're right,” added Cathy. “It’s no miracle, but we know there are so many benefits. And, yeah, it can sometimes be hard. It's easy to put off too, another thing to do later. But it's no good leaving it too late to exercise, and to think about your body when you're 65. You need to do it now. And that's another reason why I've put plans in place to keep being active.”

“What type of plans then?” asks Sarah.

“As I’ve said, I’ve contacted organizations. I’ve spoken with friends. They helped me move to an apartment near a bus stop. That makes getting to places like the gym much easier. And I feel safer. I’ve also found how to be active regularly, and keep myself motivated, by 
saying on a Sunday for instance, 'Right. This week I'll do 20 minutes of aerobic exercise at the gym on a Monday afternoon after work. On Tuesday after work, I'll do strength training. I'll do 3 sets of weights, with each set being 8 to 10 reps. Wednesday will be a day off. I often go shopping then though for some basic groceries, and wheel myself to the shop. Thursday morning before work I'll do 20 minutes of exercise on the bike in my house. And Friday after work I'll do strength training at the gym. I'll again do 3 sets of weights, with each set being 8 to 10 reps.”

“Why that amount?” asks Jennifer.

“That's what the experts recommend. I find it just right too in terms of time and energy levels. So I do two sessions of aerobic exercise for 20 minutes plus two sessions of strength training each week. And it's best not just to do exercise gently, but to work out at a moderate to heavy intensity. You really need to feel your breathing and heart rate harder and faster than usual. That's what you need to have real fitness benefits.”

“I see what you're saying, but the gym isn’t really for me. And I don’t have insurance like Jennifer,” says Sarah.

“The gym does cost. And let’s be honest, it’s not for everyone either even if you’ve got the money. But there are so many different activities we can do, and do. I was amazed when I found out how many.”

“Such as?” asks Sarah

"Wheeling for one. Rather than getting the bus everyday, or taking taxis, I know lots of people who wheel places daily, even if it's 20 minutes there and back to the corner store. And then there is swimming, water exercises, free weights at home, weight machines, elastic resistance bands, hand cycle, cycling, craftsmanship, and gardening.”

Scratching her forehead, Sarah declares, “I think if I’m going to be active physically, I'd want to play sports. But I don’t enjoy the wheelchair basketball that's always thrown out.” 
“There are so many sports too. Athletic racing, wheelchair fencing, skiing, sitting volleyball, and my friend loves tennis. She’s not competitive. She just plays for fun and loves it. There are lots of people like her I've met. And there are lots too that like the competitive side. I think the key is to find out which sport is for you. And of course, there are also the other options like I’ve said. There is wheeling, weights, and gardening for example.”

“Thanks Cathy,” says Sarah. “I’m really glad we’ve met. It’s put Krista’s advice to start planning to be active into context. I know she’s an expert, but it’s really helped hearing all about this. As I said, I've not been one for exercise or sports in the past. But I can see the benefits. I think I'm going to start exploring the options you've said.”

Shifting in her wheelchair seat Cathy adds, “And start planning now with the help of organizations, insurance companies, community centers, friends, and other people who are in our boat. And remember it can be fun!”

“Thanks Cathy,” Jennifer and Sarah say in unison.

“Thanks for being there,” adds Jennifer. “Unfortunately I’d like to chat more. But I’ve got to dash. I've an OT appointment. Is it good to meet the same time next week in here?” Nodding, and with a smile, Cathy says, "I'll be here. Take care, and see you soon.”

“You too,” replies Jennifer, before adding, “And see you later Sarah. It would be good to talk and catch up. Maybe we can look on the internet together tonight about exercising when we leave here.”

“Good idea. See you after dinner. Bye for now Jennifer,” says Sarah.

“Bye all,” Jennifer adds with a wave, before maneuvering her wheelchair from underneath the table and pushing her way to the OT department.

\section{Jack, Greg and Martin}

Jack moves through the maze of the rehabilitation hospital. The wide and long corridors are drenched in sun. In the warm air, wafts of disinfectant mingle with the odor of 
bodies that, like in care homes for the elderly, lie still for hours at a time. Large framed pictures of disabled people smiling with their family, playing sport, and offering warnings of the dangers of smoking hang on the plain white walls.

As Jack moves further through the corridors, his thoughts turn, as they so often do, to the words that changed his life forever. "You'll never walk again,” the doctor had told him as he lay still on his back. It had been two long months since his spinal cord was damaged after diving into a swimming pool. The injury had left him with no movement or feeling from the waist down. He had lost control of his bladder and bowels. He was a 21 year old man who now depended on others for basic bodily needs. During the two months of living in the spinal unit, black thoughts, anger, self-pity, despair, despondency, loneliness, fear, and feelings of frustration with his uncontrollable body often swirled through his being. There were, however, good times and days in the spinal rehabilitation hospital too. There was a mixture of feelings of joy and gratitude to hospital staff. His relationships with friends and family seemed stronger. There were also times when he felt resilient and hopeful that life would turn out well. And when he compared himself to some other spinal injured men who couldn't use their hands or breathe on their own, he felt, at times, fortunate.

Propelling himself further through the corridors in his wheelchair, moving deep into the south side of the rehabilitation hospital, Jack's thoughts evaporate as he reaches his destination. The large glass door at the end of the corridor opens automatically as he approaches with a gentle whssssssshhhhhh sound. With a short, sharp push of the metal wheel rims, he moves through the door, into the hospital's small garden. He inhales deeply. The warm breeze that gently strokes his face is rich with the scent of freshly cut grass. His nostrils also catch the smell of the Baby Powder that nurses had used and dusted onto his pressure care areas an hour ago. Jack takes another breath, and pushes himself along the smooth pavement to the far right corner of the neatly kept garden. Sun bathes his face. 
Alone in the peace and quiet of the garden, slouched in his wheelchair, Jack pushes his hand into the waistband of his thick cotton jogging pants that holds his pack of cigarettes and lumbers to pull out the Marlboros. "Damn fingers," he mutters under his breath. "Come on, move, you can do it.” A few minutes later, after the struggle with the waistband, the cigarette packet, and then the lighter, he lights up the Marlboro and draws deeply on it. The heavy sweetish tobacco soon hits his tongue. Then right on schedule he hears the whir of the spinal unit door open.

"Pass me a cigarette,” Greg calls out as he wheels himself through the door, and moves closer to join.

“You ever going to buy your own?” asks Jack, his voice flecked with laughter.

Greg and Jack had become friends over their time in the spinal hospital. While Greg was a few years older than Jack, married, they were in the same boat physically. Greg was a great source of information. He was also fun to be around. He was always willing to listen to Jack, even when he was having a bad day. But Greg, staff had assured him, was soon ready to leave the spinal hospital. He had recently spent three days 'out there' in 'the real world'. Jack knew he’d miss him, and his stories, terribly.

“Come on pass me a cigarette. You can afford it,” Greg says facing Jack. Smiling playfully, he adds, “Educated guys like you get all the luck. The money you'll get from the insurance will set you up buddy. Me, no cover, so stop your moaning.”

With the tips of his fingers, Jack tosses a cigarette, and then the lighter across onto Greg's lap. With a gentle smile, Jack asks, "So what are you going to do buddy, for money, and all that?”

"I’m not yet sure.” Wanting to change the conversation, Greg adds, "You mentioned yesterday that you might meet up with your peer support volunteer. What's his name? 
“Oh you mean Frank. He’s a good guy. Frank’s been out of here now for a year, I didn't realize that. Y'know, having support from guys like him who have been through what we're going through, well, I'm glad we have the chance to chat with them.”

"Yeah. The peer support guy that came in and buddied up with me was a huge help. He could be a bit of a jerk though sometimes,” says Greg with a smile.

Laughing, Jack added, “Yeah, but can’t we all.”

“Nah, I’m Mr. Perfect, didn’t you know,” Greg said with a laugh. “Anyhow, sorry, carry on buddy.”

“Frank got me thinking about life outside of here a bit more, like, we've been talking about physical activity, exercising. I really hadn’t thought much about it, not at all really. But we started talking, and Frank said how he'd become more physically active over the last few months. He mentioned other guys he'd met too who had found being active good for them. Well, they did find it difficult at first he said, but that's not unusual. After a while though, these guys who are in the same boat as us really enjoyed it, found it fun. And Frank mentioned the benefits he'd got from being active after his injury, like having better, stronger muscles, being able to push up steeper ramps easier, helping with pressure sore management. He also said himself it had made giving up these things a little easier,” added Jack, waving his half smoked cigarette. "And there are other knock on effects he mentioned.”

“Such as?” Greg asks, leaning forward.

"Frank really noticed benefits with his girlfriend, and he was able to hang out with friends more because he felt rejuvenated after exercising. He felt good about himself now, more confident, and could see a brighter future. I’ve really noticed the change in him too. And he takes less medication now, sleeps better, and has begun to see how he might have a purpose in life. He knows too, from what experts tell us, that being active helps lessen muscle 
loss, reduce body fat, improve flexibility, and decrease blood clots. Experts have also found that being active decreases the risk for heart disease and diabetes.”

Raising his eyebrows, Greg cut in, “Look, I’m contemplating all this, and even tried, well kind of, the gym when I left here for those three days. But come on man, you're talking as if exercise is like some miracle cure. We both know it's not. I'm not having anyone preach at me either, ramming stuff down my throat.”

“Don’t get me wrong. I’m with you bud. But you know Frank, preaching, getting on a soapbox, isn't his style. If it was I'd probably have told him to piss off.” Smiling, Jack adds, “Anyhow, I’ve decided I'm going to give it a go. What really do I have to lose?”

"I suppose nothing.”

"Yeah. So I'm intending to go for it when I leave this place, be active, and really make a go of it.” Throwing his cigarette butt in the terracotta pot brimming with other finished cigarettes, he adds, "I’m putting plans in place now, like how much exercise I need to do, how I can do it, costs, that kind of stuff.”

“Good idea,” says Greg nodding. "My time out there for those three days was hard. I thought that everything we've had to learn in here could be transferred easily out there. But no. It was like walking into darkness. Unlike in here, there were sometimes no descent ramps. There wasn't one to get into my local bar by myself. And as I said, I went to a gym on my time away from here. Well, that experience nearly put me off exercising for life. I couldn’t get there first of all. I was so used to driving everywhere.”

“So what happened?” asks Jack.

"It was, well, the thought of going out there and exercising was just overwhelming I suppose. I kinda lost all motivation too.” Tossing his own finished cigarette in the direction of the terracotta pot, Greg adds, "My wife was out at work, but later on a buddy dropped by, and we got talking. He's a good guy, and offered to take me there. I couldn't say no. So 
anyhow, my buddy takes me to one of those fancy gyms, out at one of those big box shopping centres. I went in and asked if I could look around. They obviously hadn’t dealt with someone like us before. They treated me as if I were a kid, or just completely stupid, some sort of idiot. The guys in there were patronizing as hell in how they spoke to me.”

“What do you mean?” Jack asks, leaning closer.

"This young guy, for example, was showing me around, and he went past the weights section. He just said to me, 'You obviously won’t be using these, so I won't bother explaining.' I was so pissed off! And then I couldn't get in the air-conditioned weights room. The lift was out of order. What good is the gym to me now then?” Greg snapped, before adding, “Well, I can’t afford those kind of gyms anyway. So what's the point? I don't have the energy to keep battling like that.”

“Come on man. None of that's your fault. It's not your fault the gym guy had a bad attitude or the gym was badly managed and designed. That's not your fault. It's theirs. And as you said, these things need planning. We need to plan for an active life. It doesn't happen overnight. And there are people and organizations that can help. We don't have to go it alone. I know you don’t have insurance like I do, but I’ve been working with my lawyer and he’s been quite useful. He’s helping me plan for costing memberships and equipment that I can use. He pointed me in the direction of a few organizations. I'll e-mail them to you.”

“Thanks buddy. That'll be good.”

“And Frank passed on some websites too, for organizations like the Canadian Paraplegic Association, the Canadian Paralympic Committee, and SCI Action Canada. I mean I'd already found a couple before, but they've been a big help. No cost. They’ve tons of experience of dealing with this stuff. I was thinking about going to the gym to exercise. These organizations, like my solicitor, they recommended getting my new house close to a bus stop as that would make life easier, getting to a gym easier and so on. I never really thought of that. 
It also never even occurred to me that I could do other activities, not just sports or going to the gym.”

“Such as?” says Greg, glancing down at the tubby belly that had replaced his muscular stomach.

"I’ll tell you in a second. But look out, I’ve just spotted Martin.”

“Oh no. He’s not coming this way, is he?”

Before Jack could answer, the big glass spinal hospital door slowly opened. Martin emerges and wheels himself toward Jack and Greg. A few moments later, wearing a dark blue coat over a linen shirt and thick cotton jogging pants, Martin pushes himself next to Jack and Greg.

“Hi guys,” Martin mutters.

“Hi,” they both reply back in an indifferent voice.

“Cigarette Martin?” offers Jack quickly.

"Yeah, thanks. I thought you quit smoking,” says Martin between ragged gasps of breath.

“I did, but it’s a trade-off isn’t it? Smoking occasionally and a laugh, or a healthier body and feeling bored. For now I'm going with the smoking. I know I should care given what they say in here about smoking and how our bodies are not as healthy as they used to be. But right now I don't care. I'll stop smoking when I leave. I'll stop and be totally active then, as I was telling Greg.”

“I don’t see the point in all that,” Martin exclaims. Shifting his body in his wheelchair with the help of his elbows on the chair arms, and with his eyes looking into his lap, he adds, “Life’s over for us anyway. It ended the day the neck broke. What do I have to look forward to? Nothing. Just a cure. Just a breakthrough. Life’s not worth living like this...” 
Rolling his eyes, Greg looks at Jack and asks, "You were talking about planning to be active, and the different options you've found, not just sports or a fancy gym.”

“Yeah, there are so many. It surprised me. I wasn’t really that active before I ended up like this though. I didn’t enjoy sports that much either. But there are lots of activities and the experts have found that there are so many physical, social, and psychological benefits to being active.”

“That might be,” interrupts Martin. “But disabled sport isn’t for everyone. It’s not for me. It bores me. No adrenalin rush. And these guys that I see play in the gym, they're full of bravado. They're all talk.”

“I don’t know, they seem to be having fun, and getting fit,” Greg says, casually throwing thoughts into the air.

“Maybe. But, I tell you,” says Martin. “I bet they were crap at sports before they ended up in here. They were the kids at school who got picked last to play. No, disabled sport isn't for me. It's not me. Where's the skill in it? Where's the rush, the enjoyment? And anyhow, I won't be in this chair forever, so why bother playing?”

“I really hope that’s the case man,” replies Greg. “But maybe you shouldn’t put all your hope on walking again soon. Agreed, being like this can be horrible, sometimes really awful. There are plenty of times I long for my old life back. I'd jump at a cure right now. But finding one, it might not happen for a long while. We know that. You've got to make the most of life now. If a cure comes along in 10, 15 years, or whenever, then fine, we can deal with things then. But what if one doesn't?”

“Fair point. We’ve got to live life now,” Jack says before adding. “If a cure does come, if one does come, then our bodies need to be in good shape. If I let mine waste away, get fat, lose muscle, then from what I’ve read from the scientists, it will be too difficult to 
change things, for a cure to work. Anyhow, that's not my main motivation for getting my body into shape. I'm planning on being active for lots of other reasons.”

“I’m still not so sure it’s for me. I’m a bit like Martin,” Greg says trying not to overemphasize 'the bit'. “I can see your point Martin. Sport isn’t for me either, and once I’m back home, I don't have the money, good transport nearby, or a community center close by. I can’t be bothered going to the gym again. But you were saying Jack, you were saying that there are other things you can do.”

“Yeah, they’re a lot of things. A lot don’t cost a fortune either. Wheeling, lifting weights, water exercises, swimming, cycling, free weights at home, weight machines, elastic resistance bands, hand cycle, and some sports clubs, especially those who want to play mainly for fun, will provide you with equipment. Some are really competitive I hear, others just play for fun. So there're lots of options. More than I realized to be honest. You've got wheelchair rugby, sledge hockey, curling, just to name three. There are lots of different sports out there.”

“And how do you know all this?” Martin says with suspicion in his voice. "I mean, you haven’t left the hospital since you broke your neck. And do you know all this is really true, that it's good for you? We're disabled after all.”

Softly, Jack says, “Like I mentioned to Greg, a mixture of people have shared all sorts with me. Mostly it's from some of the spinal guys who come back in here as part of our peer support. Frank was one. And I've been able to get some information from the Internet and organizations on there. Ahh, I forgot to tell you Greg, I’ve finally managed to arrange a faceto-face meeting with Cassie, the physical therapist, the cute one. She’s helping me fine-tune a plan for getting active. I know how much to do now, but a little more expert advice won't do any harm.” 
“True,” says Greg, before adding with a hint of curiosity in his voice, “So, how much exercise do you need to do? I've no interest at all in being one of those exercise fanatics, training every minute of the day. That's no life. It’s not for me.”

"I’d agree buddy. But I'm intending, and this is what the experts are saying. What they recommend, and what I'm planning on doing when I leave, is strength training twice a week. I'll also work out aerobically twice a week, for 20 minutes each time, whether that's playing sport, wheeling, or cycling.”

“And how hard, surely you just can’t coast along, hardly getting out of breath?” Greg asks.

“True. There's little benefit in that. But again, what the experts recommend for strength training is 3 sets of weights, with each set being 8 to 10 reps. The aerobic stuff, as I said, twice a week, doing it at a moderate to heavy intensity. You really need to feel your breathing and heart rate harder and faster than usual. That's what you need to have real fitness benefits.”

“Ahh, ok. That's doable. I know the benefits, as you’ve said. Improving health, wellbeing, not feeling so tired, which will be useful if I can get a job, and it would be nice not to take so many pills. I'll keep it all in mind. Maybe you can tell me later on how to plan for being physically active.”

“Sure.”

“I’m sorry guys, but this is all crap. Our lives are over; don’t you get it? Exercise isn’t some miracle cure that will make the bad days just vanish with a flick of the switch. It's awful being like this, miserable, absolute misery. Being disabled, we may as well be dead. All I want to think about is walking again,” repeats Martin angrily.

“Yeah, alright buddy. I do get it. You're right, exercising or playing sport isn’t going to produce a miracle. I'm with you on that. And I’m not here to convert you Martin,” adds 
Jack. “There are a lot of barriers out there that make it difficult as Greg will tell you. It won’t be a piece of cake getting fit. But I'm going to give it a serious go, and that's what I'm planning for. I want to live as best as I can, and try to get on with my life. A prepared mind is better than an unprepared one.”

"Well, I plan on being around for a little longer. I nearly died in that car crash,” reflects Greg. "I’ll give all this some thought then."

“Right guys, I’d love to chat more, but I‘ve a meeting with the OT,” says Jack.

“I’m off now too,” Greg quickly says. "It’s getting cold,” he adds, giving Jack a small knowing nod. Quickly they head back toward the spinal unit door, leaving Martin alone in the garden.

A minute later, inside the arid heat of the unit and back with its smells, Jack and Greg stop and turn to each other. With an air of frustrated regret in his voice, Jack says "It's no wonder no one wants to spend time with him. I tell you, he needs a kick in the butt.”

“Or just a big hug,” Greg replies with a gentle smile. “Anyway, forget him. You’ve a plan to make. Being active outside this place won’t happen talking to me.”

“True,” says Jack. "C'mon, race you to the end of the corridor buddy.”

Scholars working within more creative spheres of research often argue that ethnographic creative non-fictions such as the two presented here, can stand alone and need little autopsy. That is, there is no need for author-driven analytical dissections or overt theoretical contextualisation [33]. This kind of “story-only approach” resonates with interpretive ideologies and encourages each individual reader to construct their own understandings of the storied material. This is particularly so since stories are analytical and theoretical [32-33]. Although we see great value in allowing a story to speak for itself as a theory, to show rather than to tell, we also see merit in delineating the principal ways that our 
crafted tales can progress theoretical and practical knowledge of physical activity within the spinal injured population.

One way in which we have advanced knowledge is by first identifying key findings from our research in the manner noted in the methods section and then showing these within one paper through a story. For example, grounded in our research [e.g., 1-3, 5-6, 12, 18, 24 , 26], within the ethnographic creative non-fictions a range of different physical, social and psychological benefits of engaging in physical activity were shown. These include enjoyment, increased muscle strength and cardiovascular fitness, improved mobility, pressure sore management and prevention, smoking cessation, improved social and romantic relationships, increased self-confidence, improved self-esteem, increased motivation, increased energy levels, improved sleep, an emotional outlet, finding a purpose, post-traumatic growth, development of friendships, obtaining different forms of social support, feeling of physical fatigue, decreased heart disease and diabetes risk, better bowel and bladder control, reduced pain and healthier ageing. In addition to such benefits, and to think with rather than just about [33-34] the difficulties of implementing and sustaining a physically active lifestyle, a complex range of physical, social and psychological barriers to physical activity identified in our research (e.g., 1-3, 5- 6, 14-16, 17-18, 24] were also been woven into the storied accounts. Based again on the results of the systematic search and review method of our sustained research, these include the following: personal scepticism, lack of motivation, depression, fear of further injury, low self-esteem, body image issues, lack of sporting interest, inaccessible facilities, insufficient activity provision, poor transport links, commuting safety fears, turbulent weather, fatigue, pain, lack of confidence, social stigma, inadequate finances, lack of information about available opportunities, a perceived low reward-effort ratio, and putting oneself into the restitution narrative. Thus, this paper has, for the first time, synthesized and shown in one piece the complex range of barriers and benefits associated 
with implementing and sustaining physical activity. Unlike previous explorations of physical activity barriers and benefits [36-38], we have been able to do this as the genre of ethnographic creative non-fiction is not bound by the concerns and experiences of a single study sample and can, therefore, document a more expansive, comprehensive list.

Continuing with the theme of synthesis in terms of both synthesizing results form empirical studies and synthesizing these into one paper, the swift fluidity of stories, combined with their capacity for layered conceptual accounts, has allowed us to combine a raft of other issues that would typically be beyond the focus of a single research paper. Space limitations mean that we cannot cover all the ways in which this has been done. But, for example, within each ethnographic creative non-fiction we showed the gendered and social relational nature of implementing and sustaining a physically active lifestyle shortly after SCI. Each has an overt reference to the physical activity guidelines for SCI people [23]. There are also multiple references to how these guidelines might be best communicated to people with a spinal cord injury. For instance, we purposely showed the Internet and specialist organisations as important information sources for implementing physical activity. The valuable role of health practitioners, and in particular peer support volunteers, was also illuminated. How physical activity information is delivered (methods) and whom it is delivered by (messengers) was acknowledged in the stories as critical variables in effective knowledge mobilisation [6, 22]. Integrating theory pertaining to methods and messengers with knowledge of barriers and benefits, as we done here, provides a more contextualised perspective on these fundamental concepts. Different readers are, we hope, drawn towards the ways these issues interrelate and how they might unfold within a real-world scenario. By practically situating the literature in this way, ethnographic creative non-fictions bridge the research-practice gap.

Indeed, ethnographic creative non-fiction can serve as an important method of research knowledge translation and health communication in its own right as it has great 
potential to be accessible to a wide range of different people (27, 28-29, 32). Disability scholars, health practitioners and perhaps most essentially, spinal injured people themselves, might benefit from the information the stories capture and the manner in which they do so. It can be argued that the stylistic features of our storied accounts are more engaging, and more accessible to non-academic audiences, than the scientific and realist research tales traditionally produced. There is evidence to support the assertion that the enhanced appeal of stories increases their effectiveness as means of translating knowledge. Stories generate greater emotional responses from audiences than traditional information-giving approaches [39]. Enhanced emotional engagement ensures captured attention, enhanced understanding and improved recall [40]. An audience that is fully absorbed in the story is more receptive to the health message the story portrays.

The evidence based rationale for representing research findings as stories on occasions, and disseminating research as stories in order to increase possibilities of health behavior change, is further bolstered when, as Bruner [41] argued, people have two complementary modes of thought: the logical-paradigmatic mode (involved with discovering laws and causal relationships) and the narrative mode (involved with constituting human experience, meaning-making, and the social). When research knowledge is translated into public messages, like those encouraging people to do physical activity, they are often done so by using just the logical-paradigmatic mode. To truly promote health change we need however to "tap" not just into this mode, but also the narrative mode of thought by offering stories. This move is particularly appealing because many people 'know' that physical activity is good for their health, but still do not engage it. Stories however have the capacity to not just evoke emotions but also ambush people by attracting and holding their imaginations. A story, unlike a code, guideline, or principle that teaches people to 'know' facts, asks first that the listener imagine $[37,38]$. It is this imaginative opening that can make 
stories attractive and ambushing, explaining partly why people might be willing to listen to a story, let it get under their skin, and alter their habits or embodied dispositions in ways that may make a physical lifestyle over the life course more possible.

It is also important to carefully consider what literary techniques contribute to an absorbing story, and hence one that might successfully deliver important messages related to physical activity in the spinal cord injured population. Vivid descriptions are an important means for creating a genuine sense of time, place and plot. Such authenticity is important on two levels. Firstly, it assures academics and health professionals that a story’s messages are based on actual data, that it is evidence-based. Secondly, the more authentic a story, that is the more it is judged by a recipient as relevant to their own experiences, the more likely recipients will take heed of what it has to say [42-43]. There are many ways we have attempted to incorporate vivid descriptions and thus build the authenticity of our ethnographic creative non-fictions. A primary tool is a focussed play on the human senses. For example, "wafts of disinfectant mingle with the odor of bodies" (smell); "the heavy sweetish tobacco soon hits his tongue” (taste); "he approaches with a gentle whssssssshhhhhh sound” (hearing); and "gently squeezing Jennifer’s hand” (touch). Often considered creative elements of a story, these details could not have been written without deep immersion in our expanse of raw data. The various senses are also rarely highlighted in research on disability, sport and physical activity, yet we know they are vital in developing understandings and knowledge [44]. Again, then, by illuminating the multi-sensory nature of lives, this paper adds to the literature on disability, sport and physical activity

A further literary strategy is the inclusion of specific characters and the use of dialogue between them. Appropriate characterization promotes “identification”, the process whereby a reader experiences empathy and personal association with a given character and duly adopts their goals and beliefs [44, 45]. Dialogue helps construct character and assists 
authenticity - it is, after all, how we interact in the real-world [42]. Dialogue also helps deliver a sharp pace to the story, ensuring immediacy and narrative engagement. Dialogue has further uses. Most obviously it is a tool for information giving, however it also serves the purpose of unravelling the typical cognitive processes that underpin whether or not a spinal injured person decides to become physically active. To achieve this, each story includes a naysayer, a cynic, somebody whom to a greater or lesser degree does not buy into the underlying message. The cynic’s arguments are acknowledged, respected but countered emphatically by our other characters. Petraglia [43] argues that this persuasive rhetoric of dialogue is critical to effective health promotion.

We have alluded to the potential value of ethnographic creative non-fictions in promoting physical activity in people with SCI. Although engaging and educating audiences on the benefits of physical activity are important outcomes, they do not necessarily translate to a change in behaviour. Although the use of stories as a means to behavioural change remains an emerging innovation, the limited existing research is encouraging. For example, intervention groups exposed to informative and persuasive personal narratives have demonstrated increased intentions to quit smoking [46] and reduced perception of barriers to cancer screening [47]. Critically, neither "increased intentions" nor "reduced perceptions of barriers” constitute the Holy Grail of behavioural change, albeit they are useful predictors. An important objective for future research should therefore be to explore whether stories like the two included within this article do inspire inactive individuals with SCI to become active. This is our next research move in our sustained and systematic work on SCI, physical activity, and sport.

This project was supported by a Community-University Research Alliance (CURA) grant from the Social Sciences and Humanities Research Council (SSHRC) of Canada. 


\section{References}

1. Martin Ginis KA, Latimer AE, McKenzie K, Ditor DS, McCartney N, Hicks AL, Bugaresti J, Craven BC. Using exercise to enhance subjective well-being among people with spinal cord injury: The mediating influences of stress and pain. Rehabil Psychol 2003;48:157-164.

2. Latimer AE, Martin Ginis KA, Hicks AL. Buffering the effects of stress on well-being among individuals with spinal cord injury: A potential role for exercise. Ther Recreation J 2005;39(2):131-138.

3. Martin Ginis KA, Latimer AE. The effects of single bouts of body-weight supported treadmill training on the feeling states of people with spinal cord injury. Spinal Cord 2006;45:112-115.

4. Rimmer JH, Chen M-D, McCubbin JA, Drum C, Peterson J. Exercise intervention research on persons with disabilities: What we know and where we need to go. Am J Phys Med Rehab 2010;89:249-263.

5. Smith B. Sparkes, AC.. Disability, sport and physical activity. A critical review. In: Watson N, Roulstone A, Thomas C, editors. Routledge Handbook of Disability Studies. London: Routledge; 2012. p. 336-347.

6. Smith B. Disability, sport, and men's narratives of health: A qualitative study. Health Psychol 2013: 32(1), 110-119.

7. Martin Ginis KA, Latimer AE, Arbour KP, Buchholz, AC, Bray SR, Craven BC, Hayes KC, Hicks AL, McColl MA, Potter PJ, Smith K, Wolfe DL. Leisure-time physical activity in a population-based sample of people with spinal cord injury Part I: Demographic and injury-related correlates. Arch Phys Med Rehab 2010;91:722-728.

8. Martin Ginis KA, Arbour KP, Latimer AE, Buchholz AC, Bray SR, Craven BC, Hayes KC, Hicks AL, McColl MA, Potter PJ, Smith K, Wolfe DL. Leisure-time physical 
activity in a population-based sample of people with spinal cord injury Part II: Activity types, intensities and durations. Arch Phys Med Rehab 2010;91:729-733.

9. Sparkes A, Smith B. Men, sport, spinal cord injury and narrative time. Qual Res 2003;3(3):295-320.

10. Smith B, Sparkes AC. Men, sport, spinal cord injury and narratives of hope. Soc Sci Med 2005;61:1095-1105.

11. Smith B. Spinal cord injury, the body, and narratives of recovery in mental distress. SCI Psychosoc Process 2008;20(2):18-30.

12. Smith B, Sparkes AC. Changing bodies, changing narratives and the consequences of tellability: A case study of becoming disabled through sport. Sociol Health Ill 2008;30(2):217-236.

13. Smith B, Sparkes AC. Multiple responses to a chaos narrative. Health 2011;15:38-53.

14. Sparkes AC, Smith B. Sport, spinal cord injuries, embodied masculinities, and narrative identity dilemmas. Men Masc 2002; 24:258-285.

15. Smith B, Papathomas A. Disability sport. In: Swain J, Barnes C, Thomas C, editors. Disabling barriers, enabling environments. $3^{\text {rd }}$ ed. London: Sage; in-press

16. Smith B, Sparkes AC. Men, sport, and spinal cord injury: An analysis of metaphors and narrative types. Disability \& Society 2004; 19: 509-612.

17. Sparkes AC, Smith B. Men, spinal cord injury, memories, and the narrative performance of pain. Disability \& Society, 2009; 23: 679-690.

18. Martin Ginis KA, Latimer AE, McKenzie K, Ditor DS, McCartney N, Hicks AL, Bugaresti J, Craven BC. Using exercise to enhance subjective well-being among people with spinal cord injury: The mediating influences of stress and pain. Rehabil Psychol 2003;48:157-164. 
19. Martin Ginis KA, Latimer AE, Arbour-Nicitopoulos KP, Bassett RL, Wolfe DL, Hanna SE. Determinants of physical activity among people with spinal cord injury: A test of social cognitive theory. Ann Behav Med 2011;42:127-133.

20. Latimer AE, Martin Ginis KA, Arbour KP. The efficacy of an implementation intention intervention for promoting physical activity among individuals with spinal cord injury: A randomized controlled trial. Rehabil Psychol 2006;51(4):273-280.

21. Faulkner G, Gorczynski P, Arbour K, Letts L, Wolfe D, Martin Ginis KA. Messengers and methods of disseminating health information among individuals with spinal cord injury: A scoping review. In: Berkovsky TC, editor. Spinal Cord Injuries: Types, treatments, and prognosis. Hauppauge, NY: Nova Science Publishers; 2009. p. 349-374.

22. Letts L, Martin Ginis KA, Faulkner G, Colquhoun H, Levac D, Gorczynski P. Preferred methods and messengers for delivering physical activity information to people with spinal cord injury: A focus group study. Rehabil Psychol 2011;56(2):128-137.

23. Martin Ginis KA, Hicks AL, Latimer AE, Warburton DER, Bourne C, Ditor DS, Goodwin DL, Hayes KC, McCartney N, McIlraith A, Pomerleau P, Smith K, Stone JA, Wolfe DL. The development of evidence-informed physical activity guidelines for adults with spinal cord injury. Spinal Cord 2011;49:1088-1096.

24. Sweet S, Martin Ginis KA, Latimer-Cheung AE, The SHAPE-SCI Research Group. Examining physical activity trajectories for people with spinal cord injury. Health Psychol 2012:doi: 10.1037/a0027795

25. Martin Ginis KA, Latimer AE, Francoeur C, Hanley H, Watson K, Hicks AL, McCartney N. Sustaining exercise motivation and participation among people with spinal cord injuries: Lessons learned from a 9 month intervention. Palaestra 2002;18;38-40, 51. 
26. Sparkes, A.C, Smith, B. Spinal cord injury, sport, and the narrative possibilities of posttraumatic growth. In N. Warren \& L. Manderson (Eds), Reframing disability and quality of life: A global perspective (pp. 129-143). NY: Springer: 2013.

27. Sparkes AC Telling tales in sport and physical activity: A qualitative journey.

Champaign, Il: Human Kinetics; 2002.

28. Sparkes, AC \& Smith, B Qualitative research in sport, exercise \& health sciences. From process to product. London: Routledge; 2013.

29. Caulley D. Making qualitative research reports less boring: The techniques of writing creative nonfiction. Qual Inq 2008;14:424-449.

30. Ely M, Vinz R, Downing M, Anzul M. On writing qualitative research: Living by words. London, UK: Falmer; 1997

31. Ellingson L. Engaging in crystallization in qualitative research. London: Sage; 2009

32. Hartling L, Scott S, Pandya R, Johnson D, Bishop T, Klassen TP. Storytelling as a communication tool for health consumers: Development of an intervention for parents of children with croup. Stories to communicate health information. BMC Pediatrics. 2010;10(64):1-10.

33. Smith B, Sparkes AC. Narrative analysis and sport and exercise psychology: Understanding lives in diverse ways. Psychol Sport Exerc 2009;10:279-288

34. Ellis C. The ethnographic I. Oxford: AltaMira Press; 2004

35. Grant, M, Booth A. A typology of reviews: an analysis of 14 review types and associated methodologies. Health Info \& Lib Journal 2009; 26: 91-108.

36. Stephens C, Neil R, Smith P. The perceived benefits and barriers of sport in spinal cord injured individuals: a qualitative study. Disabil Rehabil 2012;

DOI:10.3109/09638288.2012.669020.

37. Vissers M, van den Berg-Emons R, Sluis T, Bergen M, Stam H, Bussmann H. Barriers to 
and facilitators of everyday physical activity in persons with a spinal cord injury after discharge from the rehabilitation centre. J Rehabil Med. 2008 ;40:461-7.

38. Levins SM, Redenbach DM, Dyck I. Individual and societal influences on participation in physical activity following spinal cord injury: A qualitative study. Phys Ther 2004;84:496-509.

39. McQueen A, Kreuter, MW. Measuring the effects of cancer survivor stories on cognitive and affective outcomes: A structural equation analysis. Patient Educ Couns 2010;81:1521.

40. Kreuter MW, Holmes K, Alcaraz K, Kalesan B, Rath S, Richert M, McQueen A, Caito N, Robinson L, Clark EM. Comparing narrative and informational videos to increase mammography in low-income African American women. Patient Educ Couns 2010;81(1):S6-S14.

41. Bruner J. Making stories. Cambridge, MA: Harvard University Press; 2002.

42. Frank AW. Letting stories breathe. Chicago, IL: The University of Chicago Press; 2010.

43. Petraglia J. The importance of being authentic: persuasion, narration, and dialogue in health communication and education. Health Commun 2009;24:176-185.

44. Sparkes A. Ethnography and the senses: Challenges and possibilities. Qual Res Sport Exerc Health 2009;1:21-35.

45. de Graaf A, Hoeken H, Sanders J. Identification as a mechanism of narrative persuasion. Commun Res 2011;DOI:10.1177/0093650211408594.

46. Kim HS, Bigman CA, Leader AE, Lerman C, Cappella JN. Narrative health communication and behavior change: The influence of exemplars in the news on intention to quit smoking. J Commun 2012;62:473-492.

47. Dillard JA, Fagerlin A, Dal Cin S, Zikmund-Fisher BJ, Ubel, PA. Narratives that address affective forecasting errors reduce perceived barriers to colorectal cancer screening. Soc 
Sci Med 2010;71:45-52. 